Удк 338.48

\author{
A.L. Zelezinskii, O.V. Arhipova, \\ D.V. Hodos, Y.O. Vladykina
}

\section{IDENTITY AND BRANDING OF HOTELS AS A FACTOR OF PROMOTION OF SER- VICES IN THE HOSPITALITY INDUSTRY}

The search for local authenticity is a modern point of development of tourist destinations, which forms a tourist flow, brings regular income to the local budget and develops social infrastructure. Expressed in all visual interpretations, including the brand, it allows you to "launch" and make investmentattractive regions that are completely different in terms of starting conditions. A unique selling proposition, built taking into account the integration into the overall architecture of the territorial brand, allows hotel enterprises to fully function in the high-risk and highly competitive market of hotel chains. The purpose of this article is to determine the position of small and medium-sized hotels at the local level, allowing them to compete in the market of mass hotel services.

Keywords: competitive advantages, branding, identity, domestic tourist flow, authenticity, socio-economic development.

\section{А.Л. Зелезинский ${ }^{1}$, О.В. Архипова ${ }^{2}$, Д.В. Ходос ${ }^{3}$ Ю.О. Владыкина ${ }^{4}$ \\ АЙДЕНТИКА И БРЕНДИНГ ГОСТИНИЦ КАК ФАКТОР ПРОДВИЖЕНИЯ УСЛУГ ПРЕДПРИЯТИЙ ИНДУСТРИИ ГОСТЕПРИ- ИМСТВА}

Современной точкой развития туристских дестинаций, формирующей туристский поток, приносящей регулярные доходы в местный бюджет и развивающей социальную инфраструктуру, является поиск местной аутентичности. Выраженная во всех визуальных интерпретациях, в том числе бренде, она позволяет "запустить" и сделать инвестиционно-привлекательными совершенно различные по стартовым условиям регионы. Уникальное торговое предложение, построенное с учётом встраивания в общую архитектуру территориального бренда, позволяет гостиничным предприятиям полноценно фуннционировать на высоко-рисковом и высоко-конкурентном рынке гостиничных сетей. Задачей настоящей статьи является определение позиции малых и средних отелей местного уровня, позволяющей конкурировать на рынке массовых гостиничных услуг.

Ключевые слова: конкурентные преимущества, брендинг, айдентика, внутренний турпоток, аутентичность, социальноэкономическое развитие.

DOI: 10.36807/2411-7269-2021-2-25-63-70

\footnotetext{
${ }^{1}$ Зелезинский А.Л., доцент кафедры менеджмента и маркетинга, кандидат педагогических наук; Федеральное государственное бюджетное образовательное учреждение высшего образования "Санкт-Петербургский государственный технологический институт (технический университет)", г. Санкт-Петербург

Zelezinskii A.L., Associate Professor of the Department of Management and Marketing, PhD in Education; Federal State Budgetary Educational Institution of Higher Education "Saint-Petersburg State Technological Institute (Technical University)", Saint-Petersburg

E-mail: uchposob@yandex.ru

${ }^{2}$ Архипова О.В., профессор кафредры гостиничного и ресторанного бизнеса, доктор философрских наук, доцент; ФГБОУ ВО "Санкт-Петербургский государственный экономический университет", г. Санкт-Петербург

Arhipova O.V., Professor of the Department of Hotel and Restaurant Business, Doctor of Philosophy, Associate Professor; Federal State Budgetary Educational Institution of Higher Education "Saint-Petersburg State Technological Institute (Technical University)", Saint-Petersburg

E-mail: olva@list.ru

${ }^{3}$ Ходос Д.В., профессор кафедры экономики и организации производства, доктор экономических наук, доцент; ФГБОУ ВО "Санкт-Петербургский государственный технологический институт (технический университет)", г. Санкт-Петербург

Hodos D.V., Professor of the Department of Economics and Organization of Production, Doctor of Economics, Associate Professor; Federal State Budgetary Educational Institution of Higher Education "Saint-Petersburg State Technological Institute (Technical University)", Saint-Petersburg

E-mail: hodos1@rambler.ru

${ }^{4}$ Владыкина Ю.О., доцент кафедры технологий управления, кандидат экономических наук, доцент; ФГБОУ ВО "Санкт-Петербургский государственный аграрный университет", г. Санкт-Петербург

Vladykina Y.O., Associate Professor of the Department of Management Technologies, PhD in Economics; Federal State Budgetary Educational Institution of Higher Education "Saint-Petersburg State Agrarian University", SaintPetersburg

E-mail: j_vladikina@ngs.ru
} 
В ситуации экономической нестабильности, как внутренней, так и внешней, при возрастающих политических рисках главной задачей можно считать продвижение отечественного туристического потенциала на перспективных на сегодняшний день для России рынках и экспорт туристских услуг [1]. В постоянно меняющейся внешней среде необходимо генерировать новые идеи и активно использовать современные технологии для дальнейшего развития туриндустрии. При успешном внедрении они могут превратиться в сервисный продукт, необходимый для дальнейшего развития отрасли.

Гостиничный бизнес - важнейшая часть индустрии гостеприимства. В условиях глобализации, быстрой смены трендов, усиления конкуренции, всё большее значение приобретает рациональное и грамотное управление финансовыми и производственными ресурсами гостиничного предприятия для обеспечения его эффективной работы, а именно, бесперебойного распределения денежных средств, качественной кадровой политики и сохранения ключевых конкурентоспособных показателей.

В настоящее время индустрия гостеприимства переживает сложный период. Кризис, вызванный пандемией коронавирусной инфекции COVID-19, неустойчивость цен на нефть и, как следствие - нестабильность курса доллара и евро, по прогнозам Всемирной туристской организации, могут способствовать сокращению туристических прибытий на 30-40 \% в 2020-2021 г. по сравнению с показателями 2019 г. Организация сообщает, что вероятным последствием этого станет падение выручки в туристской отрасли на $\$ 300-450$ млрд, - что составляет треть от выручки 2019 г. (\$1,5 трлн). Подводя итог, UNWTO отмечает, что таким образом будут потеряны 5-7 лет уверенного экономического роста в туриндустрии [2].

Обращаясь к истории, и сравнивая последствия подобных событий, например, вспышки атипичной пневмонии в 2003 г. и глобального экономического кризиса в 2008 г., следует отметить, что последствия несли не столь трагичный эффект. Согласно статистке UNWTO, количество туристских поездок в мире сократилось лишь на 0,4 \% и 4 \% соответственно. История показывает, что на протяжении всего развития гостиничная индустрия часто сталкивалась с кризисами. Каждый последующий кризис создавал новые возможности для туризма. Показатели национального дохода, уровень занятости, темпы развития производства и размеры прибыли не являются экономическими константами. На каждом этапе развития экономики кризисы проходят с разной степенью сложности и различными вариантами проявления. А каждый этап характеризуется своими временными границами и качественными особенностями. Для первого наиболее важна продуманная система антикризисного управления, второе же определяется закономерной последовательностью возникновения новых свойств в развитии фирмы.

Прогнозируемый в конце 90-х гг. рост туристского потока и вхождение России в ТОП-20 [3] стран туристского прибытия, сегодня даёт 15-19 \%, а по некоторым экспертным оценкам 20-25 \% ежегодного прироста туристов. Основные туристские прибытия приходятся на граждан Китая, Германии, Южной Кореи, Ирана, Индии (Рис. 1), перспективными странами можно считать Канаду, США, Францию, Италию, Великобританию, Финляндию и ряд других [4]. В количественном отношении суммарный внутренний турпоток внутри России в 2019 г. ожидался на уровне 30 млн чел. и выше, особенно в восточной части страны, благодаря внедрению электронных виз и упрощению пересечения границ [5]. 


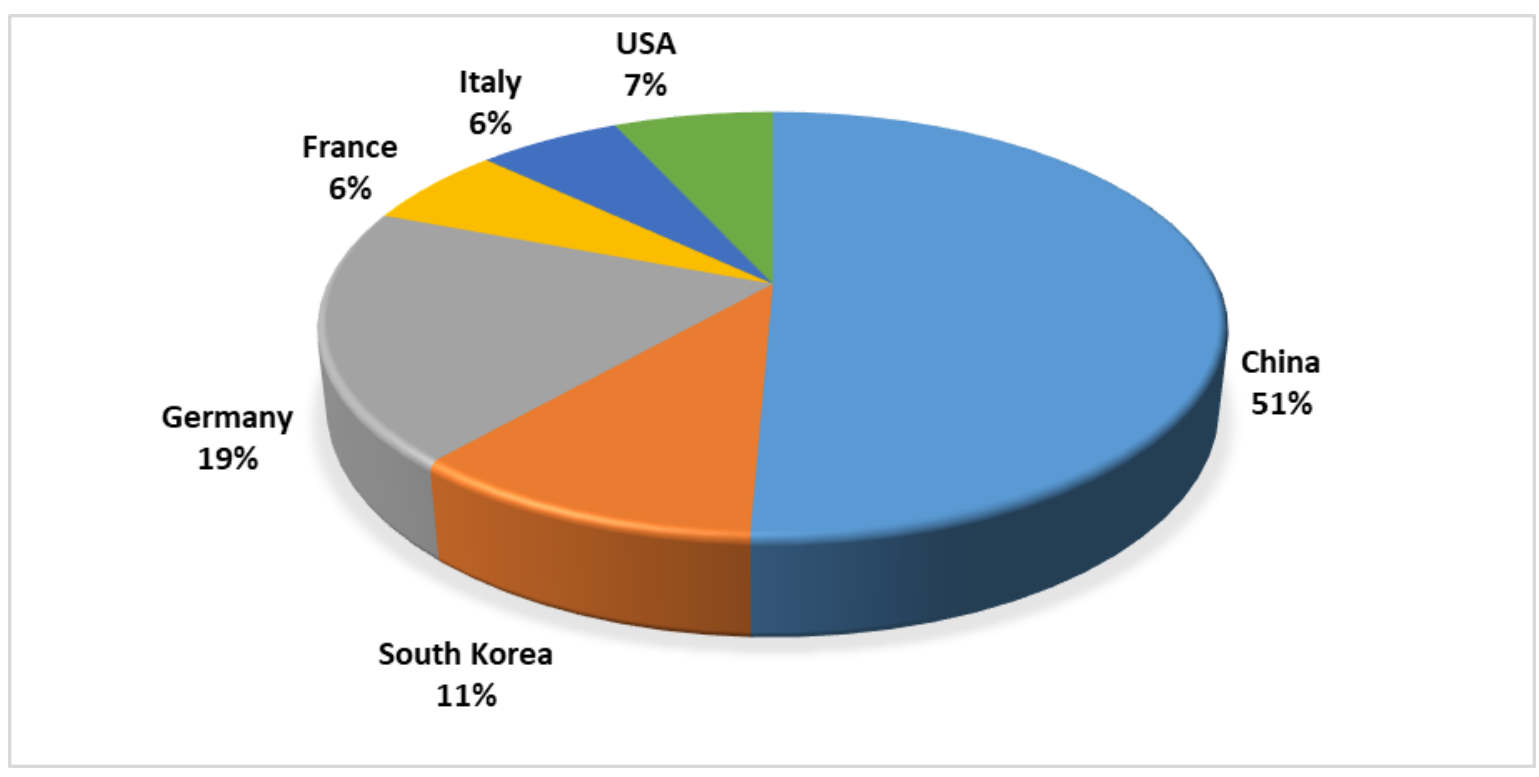

Рис. 1 - Формирование въездного и внутреннего турпотока в России, 2018 г.

Однако если учесть, что 25-30 млн чел. потенциальных туристов, из которых только 30 \% являются въездными, достаточно неравномерно распределяется по территориям, предпочитая Москву и Санкт-Петербург (до 75 \% общего турпотока), а оставшиеся 25 \% - по известным природно-рекреационным дестинациям международного уровня (Байкал, Камчатка и т.д.), то становится очевидным, что региональные туристские дестинации могут рассчитывать только на деловые поездки, либо активность потенциальных дестинаций с запуском "заодно-объектов" для увеличения и стабилизации потоков. В этих условиях включение в конкурентную борьбу сетевых гостиничных операторов (Ibis, Hilton, Radisson и др.), особенно с предложениями линейки экономкласса, не просто мешает, но дестабилизирует работу местных отельеров, вплоть до полного закрытия отелей.

Полноценная конкуренция в таких условиях невозможна, поскольку "сетевики" пользуются международными базами лояльных клиентов, которые пополняются за счёт небольшого местного спроса.

Приоритет выбора в сторону Москвы, Петербурга и курортов Черноморского побережья очевиден (Рис. 2). Для регионов остаётся примерно 4,5 млн чел. от прогнозного турпотока - это и есть рынок региональных отельеров.

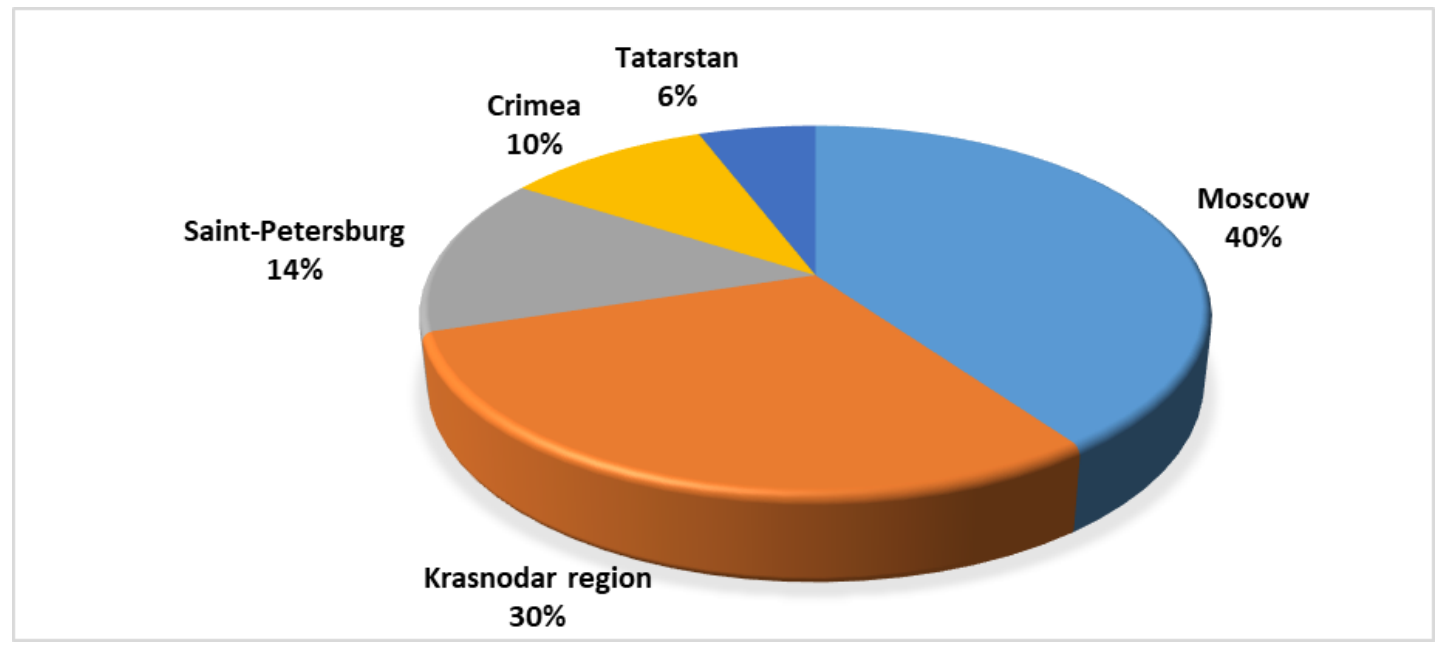

Рис. 2 - Распределение общего числа туристов по регионам России, 2017 [2], [3],

Ограниченный туристский поток в регионы обусловлен как транспортной концентрацией, так и стандартным поведением классического туриста "в одну страну - один раз", а также концентрацией аттрактивных объектов в столичных городах. Для региональных дестинаций выход из ситуации - это проведение инвентаризации возможностей и 
поиск тематик узкого целевого сегмента, для долгосрочной работы. Данное предположение основано на том, что брендированные регионы вызывают, очевидно, больший интерес у сограждан и внешних туристов. При этом бренд, способствующий формированию туристских потоков, как правило, должен затрагивать все стороны социальноэкономической, политической, культурной, историко-географической жизни региона.

В готовом виде таких регионов почти нет. Существует несколько категорий регионов по степени проработанности бренда. Это так называемая "Старая гвардия" [6], когда регионы и муниципальные образования, пользуясь образами советского периода, прочно ассоциируются у россиян с определёнными видами туризма, куда за многие десятилетия сорормировался устойчивый туристический поток. Кроме того, существуют дестинации "Переходники", к которым относятся города и регионы, туристическая индустрия которых основывалась на определённой тематике, утратившей с годами свою популярность у россиян. В результате достопримечательности есть, а туристов мало. Кроме того, есть регионы "Отшельники", которые при всей уникальности остаются в стороне от бурной туристической деятельности в силу удалённости и дороговизны пассажирских перевозок из крупных российских городов.

В настоящей статье объектами исследования туристской привлекательности выбраны Архангельская, Вологодская, Новгородская, Псковская, Томская и Кемеровская области и республики Тыва и Хакасия, относящиеся к территориям "Скрытого резерва" и "Чистого листа". Выбор данных территорий Северо-Западного и Сибирского федерального округов обусловлен схожестью климатических, транспортно-логистических, социально-экономических условий функционирования. Территории "Скрытого резерва" действительно имеют значимые объекты показа, но не имеют мощной рекламной поддержки из прошлого - "раскрутки" со стороны государства - и по этой причине сегодня они не слишком популярны среди россиян, кроме жителей своего региона и ближайших соседей, тем более среди иностранных туристов. Сюда, из рассмотренных, можно отнести: Архангельскую, Вологодскую области, республики Тыва, Хакасия и др. Территории "Чистого лиcma" - это города, районы и регионы, вступившие на путь активного развития туризма совсем недавно, и в отношении которых у основной массы российских туристов ещё не выработалось каких-либо внятных представлений. Сюда можно отнести Новгородскую, Псковскую, Томскую, Кемеровскую области, отдалённые от центральных транспортнологистических узлов, и сохранившие достаточный уровень культурно-исторических и природно-рекреационных ландшафтов. Актуальными задачами для них являются не только позиционирование на фоне аналогичных предложений с разъяснением дороги к дестинации и корректировки стереотипа об отсутствии сервиса, но и объёмные вовлечения различных институциональных структур экономики и общества в формирование территорий, привлекательных для инвестирования и жизни.

Задачей настоящей работы является определение позиции малых и средних отелей местного уровня, позволяющей конкурировать на рынке массовых гостиничных услуг.

Процесс самоидентификации при помощи туризма возможен и через другие способы формирования имиджа. Конкуренция за туристов и инвесторов, через готовый или формирующийся бренд, далеко не всем компаниям даёт возможность вписаться в структуру дестинации и удерживать активную позицию. Средства размещения, являющиеся внутренним звеном этого процесса, как правило, встраиваются в так называемый "общий поток" только после серьёзной внутренней работы. Большая часть предприятий всё же предпочитает делать акценты на качестве дизайна, сервиса, вложений в рекламу, работе персонала, предполагая тем самым закрепить лояльность клиентов. Однако все перечисленные способы не выделяют объекта из общего ряда и не позволяют выбрать дестинацию в качестве приоритетной.

Анализ степени сформированности брендов территорий позволил сделать сравнительные выводы об отношении к потокам в качестве внутри исследуемых регионов. Далее были проведены оценки возможных направлений брендирования отельных предприятий регионов. Оценка проводилась методом фокус-групп по установленным критериям, результаты оценки отражены в диаграммах (Рис. 3, 4). 


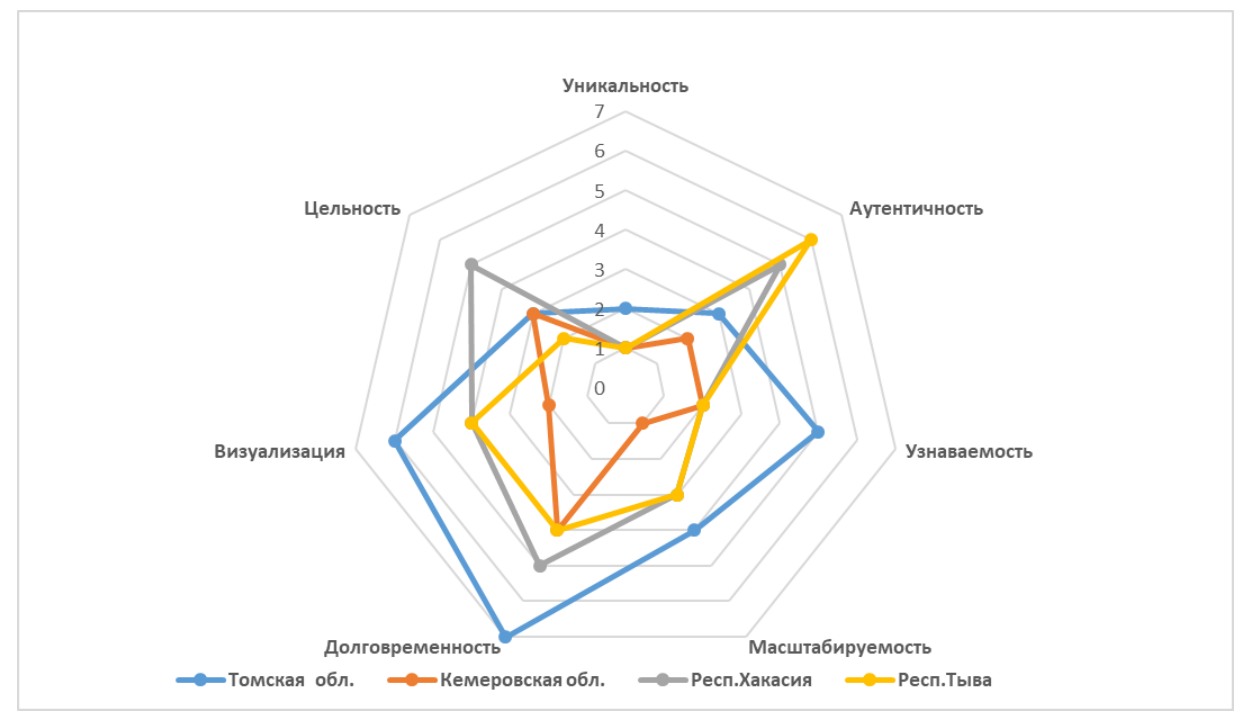

Рис. 3 - Оценка степени сформированности брендов в СФО

В оценке территорий видно, что по фракторам "Визуализация", "Долговременность", "Масштабируемость" и "Узнаваемость" бренда, среди рассмотренных регионов, лидирует Томская область. Однако, являясь техничными составными бренда, перечисленные характеристики не дают возможности выделить Томскую область среди других Сибирских регионов на рынке потенциальных туристов. В то же время, яркая "Аутентичность" и "Целостность" Республик Тыва и Хакасия, в настоящий момент не могут быть тиражируемы, долговечны и массово узнаваемы, поскольку образ территории не имеет визуализации и, как большинство российских брендов, является скорее логотипом, чем обобщающей идеей территории.

Среди представленных критериев оценки брендов нет наиболее или наименее важных, поскольку каждый из них важен в общей структуре. И работающий бренд должен обладать всеми характеристиками в полной мере. Однако если комментировать фрактор "Аутентичности" и "Целостности", то здесь очевидной становится сохранность местной культуры, быта, народных традиций, характерных для данной природно-географической дестинации. Благодаря транспортной и информационной удалённости Республик Хакасия и Тыва фрактор аутентичности присутствует в полной мере, и для туристского продвижения территории необходимо обыграть фрактор труднодоступности территории как составную часть приключения и сервиса.

Далее были проанализированы некоторые территории Северо-Западного фредерального округа, с точки зрения существования бренда территории, влияющего на формирование туристского потока. Аналогичным образом была проведена оценка региональных брендов, как наиболее сопоставимых с СФО по указанным выше признакам. Следует отметить, что такие критерии оценки как "Уникальность" и "Аутентичность" предполагали именно качество бренда территории, а не уровень социального или культурного развития. 


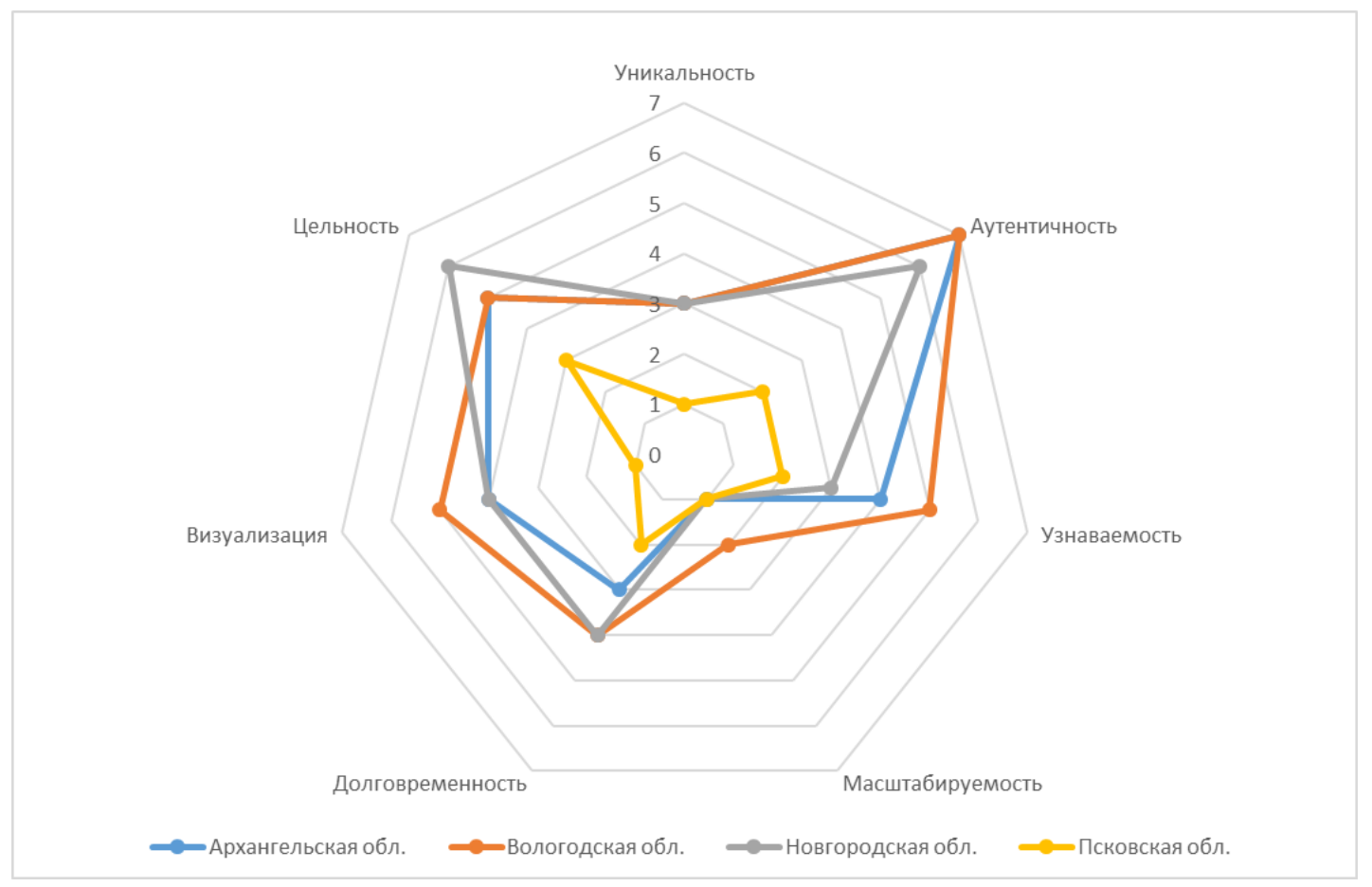

Рис. 4 - Оценка степени сформированности брендов в СЗФО

Таким образом, результат исследования показал, что бренды исследуемых территорий формируются стихийно, спонтанно, без привязки к общей стратегии развития региона, социальным запросам и инвестиционной политике. Существующие на территориях мифы, легенды, виды экономической деятельности, социальная ментальность населения позволяют предлагать и развивать некоторые направления брендирования, которые не противоречат складывающимся образам, тем более, учитывая, что в настоящий момент эти направления являются малоизученными и массово не используются в стратегиях гостиничной индустрии. В то же время на указанных территориях, как и во всех других региональных центрах, происходит процесс массового внедрения сетевого гостиничного продукта lbis, Best Western, Hilton и других международных сетей. Возникает вопрос о конкурентоспособности с сетевым сектором, имеющим обширную клиентскую базу, информационный сервис продаж, автоматизированные системы анализа доходности, накопленную базу стандартизованных операций взаимодействия с клиентами, - позволяющими довольно легко заходить на региональные рынки и вытеснять местные отели и гостиничные предприятия. Актуализируется проблема: каким образом, не имея в запасе мировых раскрученных знаков, инвестиций или дотаций, системы девелопмента, консалтинга и эфрфективного менеджмента можно конкурировать за внутренние турпотоки? Стандартный ответ: "Срочно фоомировать/восстанавливать и внедрять свои системы стандартов, овладевать навыками эффрективного сетевого управления и тиражировать бизнес-модели на внутренних территориях путём минимизации постоянных и переменных издержек и т.д. Процесс займёт от двух до десяти лет, учитывая состояние старого номерного фонда и кредитные ставки в коммерческих банках, и опыт формирования международных брендов от 20 до 60 лет. Понятно, что такая стратегия уже не поможет. В чём же выход?

Если брать за основу развивающуюся "экономику впечатлений" с неценовой конкуренцией на уровне брендов, то разработка стратегий региональных гостиничных предприятий должна включать этап присоединения (стиля, тематики, стратегии) местных гостиниц к общему бренду территории, пусть только формирующемуся, через стадию "заодно-объектов" [7], как существует в успешных проектах Золотого кольца (гостиница "Царская деревня" с "Боярскими палатами" (Сергиев Посад), отель "Дом Ершова" (Гороховец), "Пушкарская слобода" (Суздаль) с последующим включением в основную тематику территориальной дестинации. Именно такой подход положен в основу предлагаемой конкурентной стратегии региональных отелей, предложенную авторами настоящей работы (Табл. 1). 
Таблица 1 - Стратегическое брендирование регионального гостиничного продукта

\begin{tabular}{|c|c|c|c|c|}
\hline Регион & $\begin{array}{c}\text { Уровень сформи- } \\
\text { рованности де- } \\
\text { стинации }\end{array}$ & $\begin{array}{c}\text { Направление } \\
\text { формирова- } \\
\text { ния бренда }\end{array}$ & Описание бренда & $\begin{array}{c}\text { Возможные } \\
\text { тематики } \\
\text { брендирова- } \\
\text { ния отелей }\end{array}$ \\
\hline $\begin{array}{l}\text { Новгород- } \\
\text { ская область }\end{array}$ & "Белый лист" & $\begin{array}{l}\text { Русь изна- } \\
\text { чальная }\end{array}$ & $\begin{array}{l}\text { Истоки формиро- } \\
\text { вания российской } \\
\text { государственно- } \\
\text { сти }\end{array}$ & $\begin{array}{l}\text { Береста. Ле- } \\
\text { топись, Кни- } \\
\text { жичи, Русичи }\end{array}$ \\
\hline $\begin{array}{l}\text { Псковская } \\
\text { область }\end{array}$ & "Белый лист" & $\begin{array}{l}\text { Сторожевая } \\
\text { крепость }\end{array}$ & $\begin{array}{l}\text { Граничная терри- } \\
\text { тория, защищаю- } \\
\text { щая страну }\end{array}$ & $\begin{array}{l}\text { Монастыр- } \\
\text { ский пост, } \\
\text { Сторожевая } \\
\text { башня }\end{array}$ \\
\hline $\begin{array}{l}\text { Архангель- } \\
\text { ская область }\end{array}$ & "Скрытый резерв" & \multirow[t]{2}{*}{$\begin{array}{l}\text { Русский се- } \\
\text { вер }\end{array}$} & \multirow{2}{*}{$\begin{array}{l}\text { Труднодоступ- } \\
\text { ность, } \\
\text { заповедник рус- } \\
\text { ской традицион- } \\
\text { ной культуры }\end{array}$} & \multirow[t]{2}{*}{$\begin{array}{l}\text { Сирин Севера } \\
\text { Феникс }\end{array}$} \\
\hline $\begin{array}{l}\text { Вологодская } \\
\text { область }\end{array}$ & "Скрытый резерв" & & & \\
\hline $\begin{array}{l}\text { Томская об- } \\
\text { ласть }\end{array}$ & "Белый лист" & $\begin{array}{l}\text { Первоздан- } \\
\text { ная тайга }\end{array}$ & \multirow{2}{*}{$\begin{array}{l}\text { Труднодоступ- } \\
\text { ность, заповедник } \\
\text { сибирской этнои- } \\
\text { дентичности }\end{array}$} & \multirow{2}{*}{$\begin{array}{l}\text { Отшельник } \\
\text { Васюганье, } \\
\text { Белый мох, } \\
\text { Морошка }\end{array}$} \\
\hline $\begin{array}{l}\text { Кемеровская } \\
\text { область }\end{array}$ & "Белый лист" & $\begin{array}{l}\text { Скалистая } \\
\text { тайга }\end{array}$ & & \\
\hline $\begin{array}{l}\text { Республика } \\
\text { Хакасия }\end{array}$ & "Скрытый резерв" & \multirow[t]{2}{*}{ Дикая Сибирь } & \multirow{2}{*}{$\begin{array}{l}\text { Зона экстремаль- } \\
\text { ной } \text { выживаемо- } \\
\text { сти }\end{array}$} & $\begin{array}{l}\text { Степной мо- } \\
\text { гол, Сайгак }\end{array}$ \\
\hline $\begin{array}{l}\text { Республика } \\
\text { Тыва }\end{array}$ & "Скрытый резерв" & & & Саяны, Барс \\
\hline
\end{tabular}

По оценке экспертов, именно в данной плоскости лежит конкурентное преимущество, позволяющее учесть менталитет, этноидентичность культуры, запустить существующие на территории легенды и истории, активизирующие турпотоки дестинации, сохранив аутентичность регионов, избежать выхолащивания туристских территорий (как результат последней стадии освоения), очертить границы возможного для туристов и защитить территорию от издержек нарастающего глобализма.

Инфрормация - связующее звено туристской отрасли, поэтому в последние годы быстрыми темпами идёт внедрение современных информационных технологий в сферу гостеприимства [8], [9]. Их распространение существенно трансформировало стратификацию маркетинговых коммуникаций. Нужно отметить, что исходя из отмеченных выше особенностей, в частности, возрастающей роли самоуправляющихся организаций и активности физических лиц - туристов, многие изменения совершаются теперь не столько структурами и институтами, сколько за счёт деятельности людей, которые в силу жизненных обстоятельств и биографии экспериментируют с открывающимися возможностями цифровой среды коммуникации и пользуются ими. Брендирование отелей и может выступить эфффективным методом в процессе формирования конкурентных преимуществ, позволяющих отелям осознанно позиционировать себя на рынке туристских и гостиничных услуг, невзирая на отсутствие на рынке устойчивых национальных брендов.

\section{Список использованных источников}

1. Распоряжение Правительства РФ от 05.05.2018 N 872-р (ред. от 18.10.2018) Об утверждении Концепции федеральной целевой программы "Развитие внутреннего и въездного туризма в Российской Федерации (2019-2025 годы)".

2. World Tourism Organization UNWTO [Электронный ресурс] // UNWTO Highlights 2019. - Режим доступа: https://www.unwto.org/ - Загл. с экрана. - Яз. англ. (21.04.2021).

3. Результаты международного туризма 2017 года: самые высокие за семь лет. Всемирная туристская организация (ЮНВТО). [Электронный ресурс] // Режим доступа: https://media.unwto.org/press-release/2018-01-15/2017-international-tourism-results-highestseven-years / - Загл. с экрана. - Яз. англ. (04.04.2021).

4. Статистические показатели взаимных поездок граждан Российской Федерации и граждан иностранных государств. Федеральное агентство по туризму. [Электронный 
ресурс] // Режим доступа: https://www.russiatourism.ru/contents/statistika/statisticheskiedannye-po-rf-2018// - Загл. с экрана. (04.04.2021).

5. Показатели для мониторинга оценки эффективности деятельности субъектов Российской Федерации. Федеральная служба государственной статистики. Росстат. (2017). [Электронный ресурс] Режим доступа: http://www.gks.ru/free_doc/new_site/rosstat/pok-monitor/pok-monitor.html// - Загл. с экрана. (28.03.2021).

6. Макарова Н. Основные тенденции брендинга городов и регионов на туристическом рынке. Консалтинговая компания "специфика" [Электронный ресурс] // [Режим доступа:

http://www.concretica.ru/publications/single/article/4/467/?tx_ttnews\%5BsViewPointer\%5D=1\&c Hash=401сc38е02. // - Загл. с экрана. (20.03.2021).

7. Владыкина Ю.О. Экономика впечатлений: трансформация гостиничного продукта в цифровом пространстве//социально-экономические аспекты индустрии гостеприимства и модернизация образования в цифровой экономике: монография (коллективная). - СПб.: Издательство ЕТУ, 2019. - 160 с.

8. Архипова О.В. Технологические решения в гостиничном бизнесе как маркеры современной культуры // Вестник индустрии гостеприимства: научный сборник. Вып 4. СПб.: Изд-во СПбГЭУ, 2018. - 98 с. - С. 72-75.

9. Архипова О.В., Сиволап Т.Е., Терехова В.И. Маркетинг дестинаций и проблема продвижения услуг культурно-познавательного туризма // Петербургский экономический журнал: научно-практический рецензируемый журнал / Санкт-Петербургский государственный институт кино и телевидения. - СПб., 2018. - № 4. - 174 с. - С. 57-69. 